\title{
ANALISIS KESESUAIAN SOSIAL-EKOLOGIS \\ PEMANFAATAN SUMBER DAYA PERIKANAN BERDASARKAN PRODUKTIVITAS PRIMER DI KECAMATAN UNA-UNA DAN KABUPATEN TOJO UNA-UNA PROVINSI SULAWESI TENGAH
}

\author{
D. Sulistiawati ${ }^{1}$, L. Adrianto ${ }^{1}$, I. Muchsin ${ }^{1}$ dan A. Masyahoro ${ }^{2}$ \\ ${ }^{1}$ Program Studi Pesisir dan Lautan, Institut Pertanian Bogor \\ Darmaga, Bogor 16680, Indonesia Telp/Fax : 0251-624360 \\ ${ }^{2}$ Fakultas Pertanian, Universitas Tadulako \\ Jl. Soekarno Hatta km 9 Palu 94118, Indonesia Tel ./fax : 0451-429738 \\ Diterima 7 Januari 2011 - Disetujui 21 Mei 2011
}

\begin{abstract}
ABSTRAK
Memahami tingkat pemanfaatan sumberdaya alam sangat penting dalam pengelolaan sumberdaya perikanan. Penelitian ini bertujuan untuk menilai keseuaian pemanfaatan sumberdaya perikanan di Kecamatan Una-Una (lokal) dan Kabupaten Tojo Una-Una (regional). Metode yang dilakukan desk study dan survey lapang. Data yang diperoleh dianalisis menggunakan pendekatan HANPP (Human Appropriation of Net Primary Productivity). Hasil yang diperoleh bahwa HANPP lokal sebesar 7,93 $109 \mathrm{~kJ}$ dengan rasio HANPP-NPP(Net Primary Productivity) sebesar 55,50, sedangkan tingkat regional sebesar 0,93 $1012 \mathrm{~kJ}$ dengan rasio HANPP-NPP sebesar 28,17. Hal ini menunjukkan bahwa kolonisasi nelayan regional lebih efisien dalam memenuhi kebutuhan produktivitas primernya dibanding nelayan lokal.
\end{abstract}

Kata kunci : kecamatan una-una, kabupaten tojo una-una, perikanan, produktivitas primer

\section{Abstract: Analysis of Socio-Ecological Suitability of Fishery Resources Exploitation Based on Primary Productivity in the Una Una District and Tojo Una Una Regency of Central Sulawesi Province. by: D. Sulistiawati, L. Adrianto, I. Muchsin and A. Masyahoro}

Understanding level of natured resource is very important in fisheries managemant. The objectives of thist study is to assess marine fisheries exploitation in the Una-Una district (local scale) and Tojo Una-Una regency (regional scale). This research used a desk and field survey. Data obtained were analyzed using HANPP (Human Appropriation of Net Primary Productivity). Results of the study showed that HANPP at local level $7.93109 \mathrm{~kJ}$ with HANPP-NPP ratio 55.5 while HANPP of regional level was $0.931012 \mathrm{~kJ}$ with HANPP ratio of 28.17. These results indicated that a colonize regional fishers was more efficient than local fishers in appealling their primary productivity.

Keyword: social ecology, fisheries, net primary productivity, Una-una district, Tojo Una-una regency 


\section{PENDAHULUAN}

Perkembangan ilmiah yang terintegrasi berkaitan dengan interaksi sistem ekologi dan sosial yang kompleks antara manusia dan lingkungan melalui kombinasi ilmu-ilmu sosial dan lingkungan/ekologi (Haberl et al., 2001). Masyarakat sebagai penggabungan struktur alami dan sistem berbudaya, merupakan suatu unit sosial berfungsi untuk reproduksi suatu populasi manusia, baik secara fisik maupun budaya, di dalam suatu wilayah sehingga terkait dengan kedua sistem tersebut untuk memenuhi kebutuhan manusia melalui pemanfaatan sumberdaya alam (Fischer-Kowalski, et al. 2001).

Interaksi antara sistem sosial-ekologi (SSE) sangat menentukan bangun dari sumberdaya nafkah (resources livelihood) bagi nelayan di suatu kawasan. Faktor penting yang perlu dipertimbangkan juga adalah asumsi dinamik bagi kedua sistem tersebut dimana secara internal sistem sosial dan sistem ekologi selalu berada dalam kondisi yang tidak statis. Perubahan-perubahan selalu terjadi di kedua sistem sebagai akibat interaksi yang intensif berlangsung di antara keduanya (Anderies, et al. 2004).

Aplikasi dari konsep metabolisme biologi ke sistem sosial tergantung pada keberlanjutan material dan energi dalam rangka pemeliharaaan struktur internalnya (Fischer-Kowalski dan Haberl 1993). Haberl et al., (2001) memandang metabolisme sosial sebagai sistem ekonomi berkaitan dengan aliran material dan energi dan dapat dihitung dengan menggunakan pendekatan HANPP (Human Appropriation of Net Primary Production). HANPP dapat digunakan untuk menilai dampak manusia terhadap fungsi ekosistem yaitu tekanan tata guna ruang dan jasa ekosistem (produksi dan jasa pendukung). Karakteristik sistem sosial ekologi PPK (pulau-pulau kecil) dapat dipelajari dengan mengetahui intervensi sistem sosial ke sistem ekologi dan sebaliknya seberapa besar jasa sistem ekologi memberikan manfaat pada sistem sosial yang terkait dengan pemanfaatan ruang (Erb et al., 2007). Secara rasional, tata guna ruang sejauh ini memberikan pengaruh secara global terhadap perubahan siklus biogeokimia sehingga diperlukan identifikasi aktivitas manusia dan jumlah dampak yang ditimbulkan pada ekosistem dan menganalisisnya sebagai faktor pengaruh drivers sosial ekonomi (Erbet et al., 2009).

Kebutuhan produktivitas primer sistem perairan dapat dianalisis melalui pendekatan HANPP dengan menghitung PPR (Primary Productivity Requirements) (Pauly dan Christensen 1995; Wada 1999 diacu dalam Adrianto dan Matsuda 2004), dalam hal ini sebagai indikator yang mencerminkan jumlah wilayah yang dimanfaatkan manusia dan intensitas penggunaan ruang (Haberl et al., 2007). Tujuan penelitian ini adalah menilai kesesuaian pemanfaatan sumberdaya dari kegiatan perikanan tangkap pada tingkat lokal (kecamatan) dan regional (kabupaten).

\section{METODOLOGI}

\section{Lokasi dan Waktu}

Penelitian dilaksanakan di kawasan Gugus Pulau Batudaka Kecamatan Una-Una, Kabupaten Tojo Una-Una, Provinsi Sulawesi Tengah dari Bulan Juli 2009-Juni 2010. Secara geografis Gugus Pulau Batudaka terletak di tengah Teluk Tomini yang memanjang dari barat ke timur pada posisi koordinat $0^{\circ} 21^{\prime}-0^{\circ} 35^{\prime} \mathrm{LS}$ dan $121^{\circ} 35^{\prime}-121^{\circ} 58^{\prime} \mathrm{BT}$.

\section{Metode Pengumpulan Data}

Metode penelitian yang dilakukan dalam kajian ini adalah desk study dan field survey. Desk study dilakukan dalam kaitan analisis data dan analisis kajian secara keseluruhan, sedangkan field survey dilakukan untuk mengumpulkan data primer yang terkait dengan penelitian. Pengumpulan data sekunder diperoleh melalui penelusuran penelitian yang bersumber dari instansi terkait seperti: Dinas Kelautan dan Perikanan Provinsi/Kabupaten, Badan Pusat Statistik (BPS) Provinsi/Kabupaten, serta laporan hasilhasil penelitian. 


\section{Metode Analisis Data}

Profil metabolik masyarakat lokal dan regional digambarkan secara statistik melalui pendekatan HANPP (Haberl et al., 2004), antara lain berupa pertambahan dan kepadatan penduduk, produksi perikanan laut, serta tata guna ruang perairan.

Analisis metabolisme sosial - ekologis pemanfaatan sumberdaya perikanan dilakukan menggunakan pendekatan HANPP yang dikembangkan (Haberlet et al., 2002). HANPP dapat menggambarkan ekstraksi sumberdaya perikanan tangkap lokal maupun regional berdasarkan kebutuhan produktivitas primer (Primary Productivity Requirements/PPR). Formula HANPP (Haberl et al., 2002) sebagai berikut:

$H A N P P=P P R_{o}-P P R_{h}$

$\mathrm{PPR}_{\mathrm{o}}$ adalah kebutuhan produktivitas primer potensial $(\mathrm{kJ})$ diperoleh dari PPR spesies ikan (Pauly dan Christensen1995) dikalikan energi spesies ikan (kJ/100 g).
$\mathrm{PPR}_{\mathrm{h}}$ adalah produksi tiap spesies ikan (volume of landing, $\mathrm{kg}$ ) dikalikan energi spesies ikan (kJ/100 g) (Adrianto dan Matsuda 2004). Selanjutnya efisiensi tiap spesies ikan dapat dihitung dengan membandingkan HANPP dengan PPR ${ }_{h}$.

Secara teoritik, sistem perairan dibagi menjadi 6 (enam) yaitu : (1) sistem perairan terbuka (Open Oceanic System), (2) Sistem Upwelling, (3) Trophical Shelves, (4) Non Trophical Shelves, (5) Coastal and Coral System dan (6) Freshwater System (sungai dan danau). Selanjutnya dinyatakan Produktivitas Primer (PP/primary productivity) untuk masing-masing sistem tersebut adalah : (1) 103, (2) 973, (3) 310, (4) 310, (5) 890 dan (6) $290 \mathrm{gC} / \mathrm{m}^{2} /$ th. Kebutuhan produktivitas primer tiap jenis ikan dapat dihitung berdasarkan tabel referensi tiap kelompok ikan berdasarkan rata-rata trophic level (TL) dari sistem perairan (Pauly dan Christensen 1995). Untuk daerah penelitian ini, ada dua sistem yaitu Trophical Shelves dan Coastal and Coral System.

Tabel 1. Tingkat Tropik Berbagai Jenis Ikan di Gugus Pulau Batudaka

Table 1. Trophic Level of Fishes Used in the Case of Batudaka Islands

\begin{tabular}{llc}
\hline $\begin{array}{c}\text { Sistem Perairan/ } \\
\text { Aquatic System }\end{array}$ & \multicolumn{1}{c}{$\begin{array}{c}\text { Kelompok Spesies / } \\
\text { Species Group }\end{array}$} & $\begin{array}{c}\text { Tropik Level / } \\
\text { Trophic Level }\end{array}$ \\
\hline Trophical shelves & Small Pelagics & 2,8 \\
& Misc. teleosteans & 3,5 \\
& Jack, Mackerel & 3,3 \\
& Tuna, bonitos, bilifishes & 4,0 \\
& Squids, cuttlefish, octopuses & 3,2 \\
& Shrimps, prawn & 2,7 \\
& Lobster, crabs, other & 2,6 \\
& Sharks, rays, and chimaeras & 3,6 \\
& Bivalves and other mollusca & 2,1 \\
& Misc. Marine fishes & 2,8 \\
& Herrings, sardines and anchovies & 3,2 \\
& Seaweeds & 1,0 \\
& Jack, Mackerel & 3,3 \\
& Diadromous Fishes & 2,8 \\
& Shrimps, prawn & 2,6 \\
& Turtles & 2,4 \\
\hline
\end{tabular}

Sumber / Source: Pauly dan Christensen (1995)/ Pauly and Christensen (1995) 
Kebutuhan produktivitas primer atau PPR spesies ikan dihitung berdasarkan formula Pauly dan Christensen (1995), yaitu :

$$
P P R_{i}=\frac{C_{i}}{9} \times 10^{(T L i+1)}
$$

dimana PPRi adalah kebutuhan produktivitas primer spesies ikan ke-i; dan $C$ adalah hasil tangkapan spesies ikan ke-i, C dibagi 9 sebagai konversi berat atom C (Wada 1999 diacu dalam Adrianto dan Matsuda 2004); (TL-i) adalah rata-rata jumlah transfer trophic level produktivitas primer hasil tangkapan ikan ke-i.

\section{HASIL DAN PEMBAHASAN}

\section{A. Demografi}

Berdasarkan hasil sensus penduduk tahun 2001-2008, penduduk Kabupaten Tojo Una-Una mengalami peningkatan 2,39\% setiap tahunnya dan Kecamatan Una-Una peningkatan $2 \% /$ tahun. Tingkat kelahiran dan kematian yang lebih rendah dibanding tingkat pertumbuhan penduduk. Salah satu pendorong tingginya pertumbuhan penduduk adalah arus migrasi masuk yang cukup signifikan, sebagian besar adalah pendatang yang mencari nafkah di daerah ini.

Tabel 2. Parameter Demografi Kecamatan Una-Una dan Kabupaten Tojo Una-Una Table 2. Demographic Parameters of the Una-Una District and Tojo Una-Una Regency

\begin{tabular}{|c|c|c|}
\hline $\begin{array}{l}\text { Parameter/ } \\
\text { Parameters }\end{array}$ & $\begin{array}{l}\text { Lokal/ } \\
\text { Local }\end{array}$ & $\begin{array}{r}\text { Regional/ } \\
\text { Regional }\end{array}$ \\
\hline $\begin{array}{l}\text { Jumlah Penduduk } 2008 \text { (Jiwa)/ } \\
\text { Total of population } 2008 \text { (Person) }\end{array}$ & 13.106 & 131.283 \\
\hline $\begin{array}{l}\text { Kepadatan Penduduk } 2008\left(\mathrm{Jiwa} / \mathrm{km}^{2}\right) / \\
\left.\text { Population density } 2008 \text { (Person } / \mathrm{km}^{2}\right)\end{array}$ & 42 & 23 \\
\hline $\begin{array}{l}\text { Rumah Tangga (RT) 2008/ } \\
\text { Household } 2008\end{array}$ & 3.547 & 33.872 \\
\hline $\begin{array}{l}\text { Sebaran rata-rata Rumah Tangga/Population } \\
\text { density of each household }\end{array}$ & 4 & 4 \\
\hline Laki-laki/Perempuan/Sex Ratio & 104 & 104 \\
\hline $\begin{array}{l}\text { Tingkat Ketergantungan penduduk/ } \\
\text { Depedency rate of population }\end{array}$ & 67,60 & 70,24 \\
\hline $\begin{array}{l}\text { Pertumbuhan Penduduk Tahun 2001-2008/ } \\
\text { Population Growth 2001-2008 }\end{array}$ & 2,0 & 2,39 \\
\hline $\begin{array}{l}\text { Tingkat Kelahiran penduduk Tahun 2008/ } \\
\text { Fertility rate of population } 2008\end{array}$ & 0,013 & 0,0086 \\
\hline $\begin{array}{l}\text { Tingkat Kematian Penduduk Tahun 2008/ } \\
\text { Mortality rate of population } 2008\end{array}$ & 0,005 & 0,0034 \\
\hline
\end{tabular}




\section{B. Laju Tangkap dan Estimasi Produksi Perikanan}

Laju tangkap dan estimasi produksi beberapa alat tangkap yang beroperasi di perairan Kecamatan Una-Una menunjukkan bahwa teknologi yang digunakan masih tergolong sederhana, yang menyebabkan hasil penangkapan tidak maksimal (Tabel 3). produksi perikanan laut di Kabupaten Tojo Una-Una (Tabel 4).

Musim penangkapan ikan di wilayah penelitian terbagi atas dua musim yakni musim puncak dan paceklik. Musim puncak (surplus ikan) umumnya berlangsung selama 8-10 bulan yaitu pada bulan September/ Oktober sampai bulan April/Mei.

Tabel 3. Laju Tangkap dan Estimasi Produksi Beberapa Alat Tangkap yang Beroperasi di Perairan Kecamatan Una-Una Tahun 2009

Table 3. CPUE and Estimated Production of various Fishing Gear in the Una-Una District, 2009

\begin{tabular}{llcccc}
\hline No & $\begin{array}{c}\text { Alat Tangkap/ } \\
\text { Fishing gear }\end{array}$ & $\begin{array}{c}\text { Jumlah* } \\
\text { / unit* }\end{array}$ & $\begin{array}{c}\text { Trip/tahun/ } \\
\text { Trip/year }\end{array}$ & $\begin{array}{c}\text { Laju Tangkap } \\
\text { rata-rata (kg/ } \\
\text { trip)/CPUE } \\
\text { (kg/trip) }\end{array}$ & $\begin{array}{c}\text { Estimasi Produksi } \\
\text { (ton/tahun)/ } \\
\text { Estimated } \\
\text { production (ton/ } \\
\text { year) }\end{array}$ \\
\hline 1 & $\begin{array}{l}\text { Pancing/Hand } \\
\text { Line } \\
\text { Jaring Ingsang/ } \\
\text { gillnet }\end{array}$ & 211 & 120 & 10 & 304,32 \\
\hline $\begin{array}{l}\text { Bagan-jaring } \\
\text { angkat/Liftnet } \\
\text { Bubu/Fish Trap }\end{array}$ & 11 & 40 & 100 & $1.266,00$ \\
\hline
\end{tabular}

Sumber / Source: *DKP UPTD Kecamatan Una-Una (2010)/UPTD Marine Affairs and Fisheries Service Una-Una District (2010)

Berdasarkan jumlah alat tangkap yang ada di Kecamatan Una-Una maka estimasi produksi perikanan pada tahun 2009 sebesar 1.637,07 ton (Anonymous, 2009). Produksi perikanan laut Kecamatan Una-Una pada Tahun 2008 sebesar 1.123 ton (Anonymous, 2009), sedangkan menurut Bappeda Tojo Una-Una (2009) sebesar 1,759.68 ton.

Produksi perikanan laut terbesar terdapat di Ampana Kota sebesar 55.099 ton, dan disusul oleh Tojo Barat yaitu sebesar 6.383 ton (Tabel 4). Hal ini menunjukan sebagian besar hasil tangkapan nelayan dari kecamatan kepulauan di Teluk Tomini didaratkan di kecamatan tersebut. Sektor perikanan Kecamatan Una-Una memberikan kontribusi sebesar $1.56 \%$ dari seluruh
Jumlah trip penangkapan ikan tertinggi pada musim puncak dilakukan oleh unit usaha pukat cincin (purse seine) yakni 25 trip per bulan. Musim paceklik (kekurangan ikan) umumnya berlangsung selama 2-4 bulan yaitu pada bulan Mei/Juni sampai Agustus/ September. Jumlah trip penangkapan ikan pada musim paceklik pada setiap unit usaha penangkapan yakni berkisar antara 2-12 trip per bulan. Trip ter rendah terjadi pada unit usaha bagan antara 2-5 trip per bulan (Laapo et al., 2007). Ketersediaan sarana penangkapan, tenaga kerja melaut dan sarana penunjang berpengaruh pada peningkatan aktivitas dan mobilitas melaut secara intensif. 
Tabel 4. Produksi Perikanan menurut Kecamatan di Kabupaten Tojo Una-Una Tahun 2008 Table 4. Fisheries Production by District in the Tojo Una-Una Regency, 2008

\begin{tabular}{|c|c|c|c|c|c|c|c|c|}
\hline \multirow{2}{*}{ No } & \multirow{2}{*}{$\begin{array}{l}\text { Kecamatan/ } \\
\text { District }\end{array}$} & \multicolumn{2}{|c|}{$\begin{array}{l}\text { Perairan Umum / } \\
\text { Open Water }\end{array}$} & \multicolumn{2}{|c|}{$\begin{array}{l}\text { Budidaya Kolam/ } \\
\text { FreshwaterFish Culture }\end{array}$} & \multicolumn{2}{|c|}{$\begin{array}{l}\text { Budidaya Tambak / } \\
\text { BreakerwaterFish Culture }\end{array}$} & \multirow{2}{*}{$\begin{array}{c}\begin{array}{c}\text { Perikanan } \\
\text { Laut / } \\
\text { Marine } \\
\text { Fisheries }\end{array} \\
\begin{array}{c}\text { Produksi } \\
\text { (Ton)/ }\end{array} \\
\begin{array}{c}\text { Production } \\
\text { (ton) }\end{array}\end{array}$} \\
\hline & & $\begin{array}{l}\text { Luas } \\
\text { (ha)/ } \\
\text { area } \\
\text { (ha) }\end{array}$ & $\begin{array}{l}\text { Produksi } \\
\text { (Ton)/ } \\
\text { Production } \\
\text { (ton) }\end{array}$ & $\begin{array}{l}\text { Luas } \\
\text { (ha)/ } \\
\text { area } \\
\text { (ha) }\end{array}$ & $\begin{array}{l}\text { Produksi } \\
\text { (Ton)/ } \\
\text { Production } \\
\text { (ton) }\end{array}$ & $\begin{array}{l}\text { Luas (ha)/ } \\
\text { Area (ha) }\end{array}$ & $\begin{array}{l}\text { Produksi } \\
\text { (kg)/ } \\
\text { Production } \\
\text { (kg) }\end{array}$ & \\
\hline 1 & Tojo Barat & - & - & - & - & 4,10 & 400,00 & 6.383 \\
\hline 2 & Tojo & 5,10 & - & 7,50 & 0,60 & 120,00 & 1,30 & 1.901 \\
\hline 3 & Ulubongka & - & - & 13,02 & 0,40 & - & - & 953 \\
\hline 4 & Ampana Tete & 0,70 & - & 3,00 & 0,30 & - & - & 2.817 \\
\hline 5 & Ampana Kota & - & - & 19,15 & 1,20 & - & - & 55.099 \\
\hline 6 & Una-una & 10,40 & 1,40 & - & - & 20,90 & 2,80 & 1.123 \\
\hline 7 & Togean & - & - & - & - & - & - & 2.083 \\
\hline 8 & Walea Kepulauan & - & - & - & - & - & - & 852 \\
\hline 9 & Walea Besar & - & - & - & - & - & - & 558 \\
\hline \multicolumn{2}{|c|}{$\begin{array}{l}\text { Kabupaten Tojo Unauna/ } \\
\text { Tojo Una-Una Regency }\end{array}$} & 16,20 & 1,40 & 42,67 & 2,50 & 145,00 & 404,10 & 71.769 \\
\hline
\end{tabular}

Sumber : BPS kab. Tojo Una-Una (2009)/ Source: Central Bureau of Statistics of Tojo Una-Una Regency (2009)

Tabel 5. Produksi Ikan di Kecamatan Una-Una Tahun 2005-2008/ Table 5. Fish Production in the Una-Una District, 2005-2008

\begin{tabular}{|c|c|c|c|c|c|c|c|c|}
\hline \multirow{2}{*}{$\begin{array}{l}\text { Nama } \\
\text { Indonesia/ } \\
\text { local Name }\end{array}$} & \multirow{2}{*}{$\begin{array}{l}\text { Nama Inggris/ } \\
\text { English Name }\end{array}$} & \multirow{2}{*}{$\begin{array}{l}\text { Nama IImiah/ } \\
\text { Scientific Name }\end{array}$} & \multicolumn{4}{|c|}{ Volume (kg)*/ Volume of Landing (kg) } & \multirow{2}{*}{$\begin{array}{l}\text { Sistem } \\
\text { Perairan*/ } \\
\text { Aquatic } \\
\text { System }\end{array}$} & \multirow{2}{*}{$\begin{array}{c}\text { Trophic } \\
\text { Level }\end{array}$} \\
\hline & & & 2005 & 2006 & 2007 & 2008 & & \\
\hline Kerapu sunu & Grouper & $\begin{array}{l}\text { Plecrtopormus } \\
\text { leopardus }\end{array}$ & 4.346 & 5.348 & 4.229 & 3.461 & 2 & 2,8 \\
\hline Kakap & $\begin{array}{l}\text { Giant sea pearch/ } \\
\text { Baramundi }\end{array}$ & Lutjanus sp. & 7.963 & 7.880 & 5.753 & 8.060 & 2 & 2,8 \\
\hline Tongkol & Frigate mackerel & Auxis sp. & 15.200 & 12.000 & 12.600 & 15.060 & 1 & 4,0 \\
\hline $\begin{array}{l}\text { Teri/lureh/ } \\
\text { rono }\end{array}$ & $\begin{array}{l}\text { Commerson's } \\
\text { anchovy } \\
\text { (Anchovies) }\end{array}$ & $\begin{array}{l}\text { Stolephorus } \\
\text { commersonii } \\
\text { (Stolephorus } \\
\text { spp) }\end{array}$ & 6.850 & 7.700 & 6,685 & 4.500 & 1 & 2,8 \\
\hline Tenggiri & $\begin{array}{l}\text { Spotted spanish } \\
\text { mackerel (Indo- } \\
\text { pasific king } \\
\text { mackerel) }\end{array}$ & $\begin{array}{l}\text { Scomberomorus } \\
\text { guttatus }\end{array}$ & 450 & 250 & 450 & 150 & 1 & 4,0 \\
\hline $\begin{array}{l}\text { Ekor Kuning/ } \\
\text { lolosi }\end{array}$ & $\begin{array}{l}\text { Redbely Yellow } \\
\text { tail Fusilier }\end{array}$ & Caesio cuning & 6.220 & 5.150 & 4.160 & 3.831 & 2 & 2,8 \\
\hline Teripang & Sea cucumber & Stichopus spp & 2070 & 839 & 624 & 1.319 & 2 & 2,4 \\
\hline Kepiting & Mud carb & Scylla serata & 80 & 175 & 145 & 185 & 2 & 2,6 \\
\hline $\begin{array}{l}\text { Udang } \\
\text { Barong }\end{array}$ & Spiny Lobster & Penulirus spp & 585 & 75 & 560 & 115 & 2 & 2,6 \\
\hline Gurita & Octopuses & Octopus & 300 & 230 & 830 & 280 & 2 & 3,2 \\
\hline
\end{tabular}

Sumber: DKP UPTD Kecamatan Una-Una (2010)/Source: UPTD Marine Affairs and Fisheries Service Una-Una District(2010)

Keterangan/ Note : * 1) Trophical Shelves; 2) Coastal and Coral System 


\section{Profil Metabolik}

Profil metabolik dapat diketahui melalui nilai HANPP (Human Appropriation of Net Primary Productvity). Tiga langkah dalam menghitung HANPP perikanan atau disebut pula sebagai exosomatic energi yakni : (1) menghitung potensi kebutuhan produktivitas primer (2) produktivitas aktual (produksi tiap spesies ikan (volume of landing) (DKP Prov. Sulawesi Tenggara 2005-2008); (3) kandungan energi tiap spesies ikan (Adrianto dan Matsuda 2004). Produksi ikan yang tertangkap di Kecamatan Una-Una tertera pada Tabel (5) dan produksi ikan yang tertangkap di Kabupaten Tojo Una-Una dapat dilihat pada Lampiran 1. tingkat regional sebesar 0,93 $1012 \mathrm{~kJ}$ dengan efisiensi koloni ikan yang tertangkap sebesar 3,70 dan rasio HANPP-NPP sebesar 28,17. Pada ekosistem global, rasio HANPP dengan NPP potensial sekitar 40 di seluruh dunia. Tingginya rasio tersebut menggambarkan dominasi manusia terhadap ekosistem, dimana pengurangan produktivitas aktual (NPP) yang besar sebagai indikasi kurang efisiennya dalam pengelolaan sumberdaya perikanan (Haberl et al., 2004).

Besarnya HANPP perikanan tergantung dari banyak hasil tangkapan tiap jenis ikan dan kandungan energi tiap energi ikan. Efisiensi yang rendah mengindikasikan ekstraksi sumberdaya perairan menyebabkan

Tabel 6. Perhitungan Exosomatic Energy Lokal dan regional, 2005-2008/ Table 6. Calculated Exosomatic Energy at Local and regional, 2005-2008

\begin{tabular}{lccccc}
\hline Tahun/Year & PPR $_{\mathrm{h}}(\mathrm{kJ})$ & $\mathrm{PPR}_{\mathrm{o}}(\mathrm{kJ})$ & HANPP (kJ) & $\begin{array}{c}\text { Colonizing } \\
\text { Efficiency }\end{array}$ & $\begin{array}{c}\text { HANPP } \\
\text { NPP Ratio }\end{array}$ \\
\hline Lokal & $(\mathrm{kJ})$ & $(\mathrm{kJ})$ & $(\mathrm{kJ})$ & $(\%)$ & \\
2005 & 159.367 .245 & 9.010 .724 .881 & 8.851 .357 .636 & 1,80 & 55,54 \\
2006 & 141.073 .720 & 7.147 .402 .905 & 7.006 .329 .185 & 2,01 & 49,66 \\
2007 & 132.943 .895 & 7.571 .265 .020 & 7.438 .321 .125 & 1,79 & 55,95 \\
2008 & 138.459 .890 & 8.560 .915 .008 & 8.422 .455 .118 & 1,64 & 60,83 \\
Rata-rata & $\mathbf{1 4 2 . 9 6 1 . 1 8 8}$ & $\mathbf{8 . 0 7 2 . 5 7 6 . 9 5 4}$ & $\mathbf{7 . 9 2 9 . 6 1 5 . 7 6 6}$ & $\mathbf{1 , 8 1}$ & $\mathbf{5 5 , 5 0}$ \\
\multicolumn{1}{c}{ Regional } & $\mathbf{( M J )}$ & $\mathbf{( M J )}$ & $\mathbf{( M J )}$ & $\mathbf{( \% )}$ & \\
2005 & 31.623 .085 & 951.189 .626 & 919.566 .541 & 3,44 & $\mathbf{2 9 , 0 8}$ \\
2006 & 33.942 .042 & 1.020 .815 .129 & 986.873 .087 & 3,44 & 29,08 \\
2007 & 31.815 .755 & 1.137 .875 .166 & 1.106 .059 .411 & 2,88 & 34,76 \\
2008 & 36.261 .576 & $753.279,627$ & 717.018 .051 & 5,06 & 19,77 \\
Rata-rata & $\mathbf{3 3 . 4 1 0 . 6 1 4}$ & $\mathbf{9 6 5 . 7 8 9 . 8 8 7}$ & $\mathbf{9 3 2 . 3 7 9 . 2 7 3}$ & $\mathbf{3 , 7 0}$ & $\mathbf{2 8 , 1 7}$ \\
\hline
\end{tabular}

Sumber: Data Terolah (2010)/Source : Data Analysis (2010)

Hasil perhitungan exosomatic energy pada tingkat lokal (kecamatan) (Tabel 6) menunjukan bahwa rata-rata exosomatic energy perikanan dari tahun 2005-2008 sebesar 7,93 $109 \mathrm{~kJ}$ dengan efisiensi koloni ikan yang tertangkap sebesar 1,81 dan rasio HANPP-NPP sebesar 55.50. Perhitungan pada kolonisasi sosial yang lebih besar. Artinya untuk memenuhi kebutuhan produktivitas primernya nelayan lokal membutuhkan energi yang lebih besar dibanding nelayan regional. $\mathrm{Hal}$ ini berhubungan dengan penggunaan perahu tanpa motor dan alat tangkap yang sederhana pada nelayan lokal. 


\section{KESIMPULAN DAN IMPLIKASI KEBIJAKAN}

Pemanfaatan sumberdaya alam laut dan pesisir di Kecamatan Una-Una masih dilakukan dalam skala kecil (unit ekonomi keluarga) dengan alat tangkap sederhana seperti pancing, jaring, bubu dan bagan, sedangkan di Kabupaten Tojo Una-Una penggunaan alat tangkap lebih beragam. Hasil analisis HANNP menunjukkan efisiensi yang rendah pada tingkat lokal dibanding tingkat regional sehingga nelayan lokal memerlukan energi yang lebih besar dalam memenuhi kebutuhan produktivitas primernya.Implikasikebijakannya adalah perlunya dukungan teknologi maupun infrastruktur untuk menunjang kegiatan pemanfaatan sumberdaya pesisir di Kecamatan Una-Una. Kabupaten Tojo yang didominasi ikan pelagis yang memiliki karakteristik sebagai transboundary spesies, diperlukan kerjasama antar kabupaten/ kota atau antar provinsi melalui kebijakan pengaturan pengelolaan perikanan berbasis ekosistem (ecosystem-based fisheries management). Contoh kerjasama adalah pengembangan teknologi perikanan dalam konteks eksplorasi maupun pengolahan hasil perikanan.

\section{DAFTAR PUSTAKA}

Adrianto, L., and Y. Matsuda, 2004. Fishery resources appropriation in Yoron Island, Kagoshima prefecture, Japan : a static and dynamic analysis. Working Paper. Kagoshima University, Japan. 285-342p

Anderies, J.M., Janssen, M.A., Ostrom, E. 2004. A framework to analys the robustness of social ecological systems from an institutional perspective, Ecology and Society. 9 (1).

Annonimous, 2010. Data potensi perikanan tangkap dan produksi kelautan dan perikanan. Laporan unit Pelaksana Teknis Kecamatan Una-Una, Wakai.

2009. Survei sosial ekonomi daerah Kabupaten Tojo Una-Una (SUSEDA) 2009. Laporan Bappeda dan PM Kabupaten Tojo Una-Una, Ampana.
2009. Kecamatan Una-Una dalam Angka 2008. Badan Pusat Statistik Kabupaten Kabupaten Tojo Una-Una, Ampana.

Erb, K. H., Gaube, V., Krausmann, F., Plutzar, C., Bondeau, A., Haberl, H., 2007. A comprehensive global $5 \mathrm{~min}$ resolution land-use dataset for the year 2000 consistent with national census data. Journal of Land Use Science 2 (3):191-224.

Erb, K. H., E., F. Krausmann, V. Gaube, S. Gingrich, A. Bondeau,M. Fischer-Kowalski and H. Haberl, 2009. Analyzing the global human appropriation of net primary production - processes, trajectories, implications. An introduction. Ecological Economics 69:250-259p.

Fischer-Kowalski, M., C. Amann, Beyond IPAT and K. Curves 2001. globalization as a vital factor in analyzing the environmental impact of socioeconomic metabolism. Population and Environment, 23(1).

Fischer-Kowalski, M. and H. Haberl., 1993 Metabolism and Colonization. Modes of Production and the Physical Exchange between Societies and Nature. In: Innovation -The European Journal of Social Sciences 6(4):415-442.

Haberl, H., K-H. Erb, F. Krausmann, W.Loibl, N.Schulz, and H.Weisz 2001. Changes in ecosystem processes induced by land use: human appropriation of net primary production and its influence on standing crop in Austria. Global Biogeochemical Cycles 15 (4):929-942p.

Haberl, H., F. Krausmann., Erb, K. H.,N. B. Schulz, S. Rojstaczer, S. M. Sterling, and N. Moore, 2002. Human Appropriation of Net Primary Production. Science 296 (14):1968-1969p.

Haberl, H., M. Wackernagel, F. Krausmann, K-H.Erb, and C. Monfreda 2004. Ecological footprints and human appropriation of net primary production: a comparison. Land Use Policy 21:279$288 p$. 
Haberl, H., K H. Erb and F. Krausmann, 2007. Human appropriation of net primary production (HANPP). International Society for Ecological Economics. Internet Encyclopedia of Ecological Economics. http://www.ecoeco org publica/encyc.htm 1-15 (diakses tanggal 11 Juni 2011)
Laapo A, A. Masyahoro, dan J. Nilawati, 2007. Estimasi potensi ekonomi sumberdaya perikanan tangkap di perairan kab. Tojo Una-Una. Jurnal Agroland 14(2):140-144p.

Pauly, D. and V. Christensen. 1995. Primary production required to sustain global fisheries. Nature 374:255-257p. 


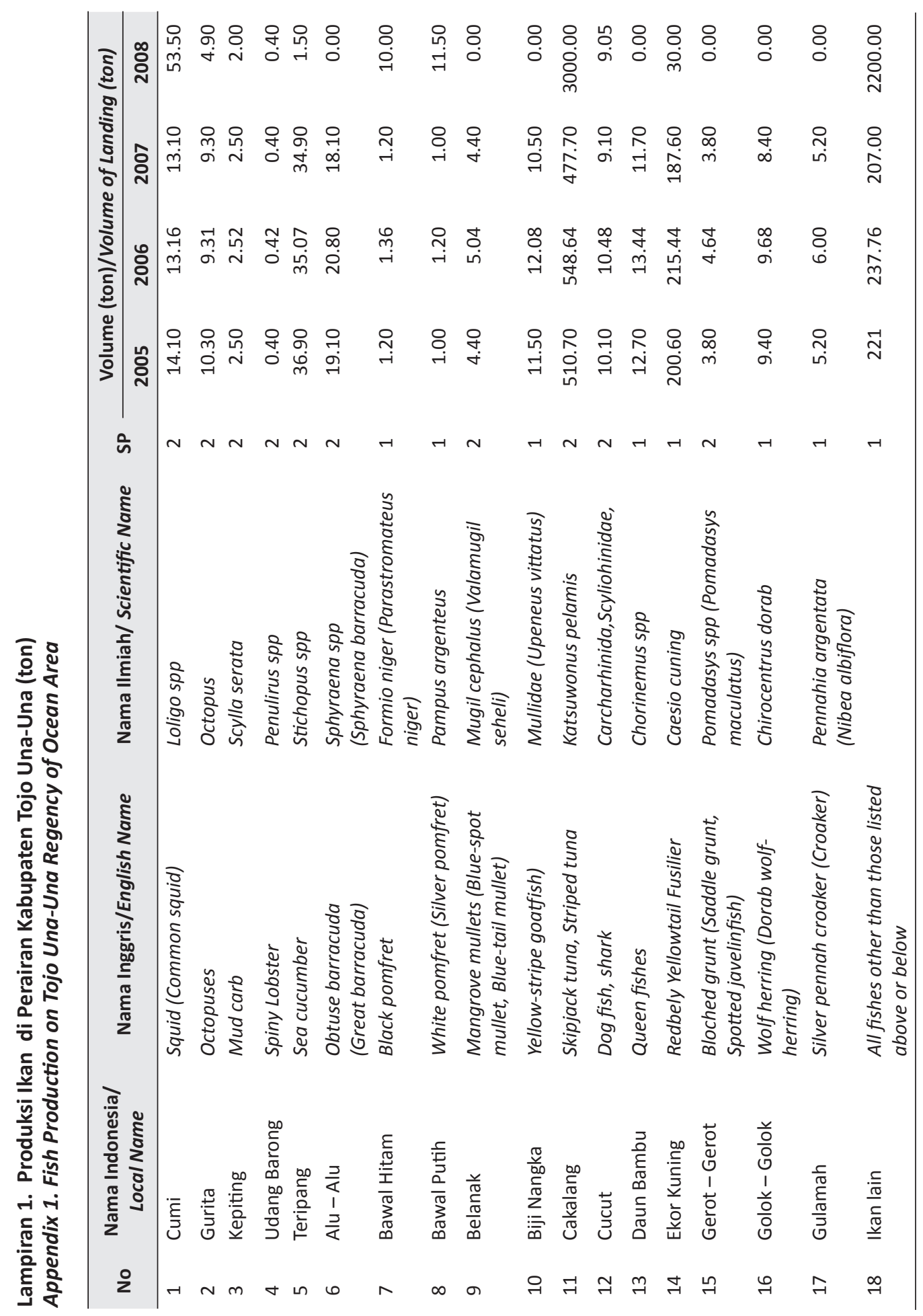




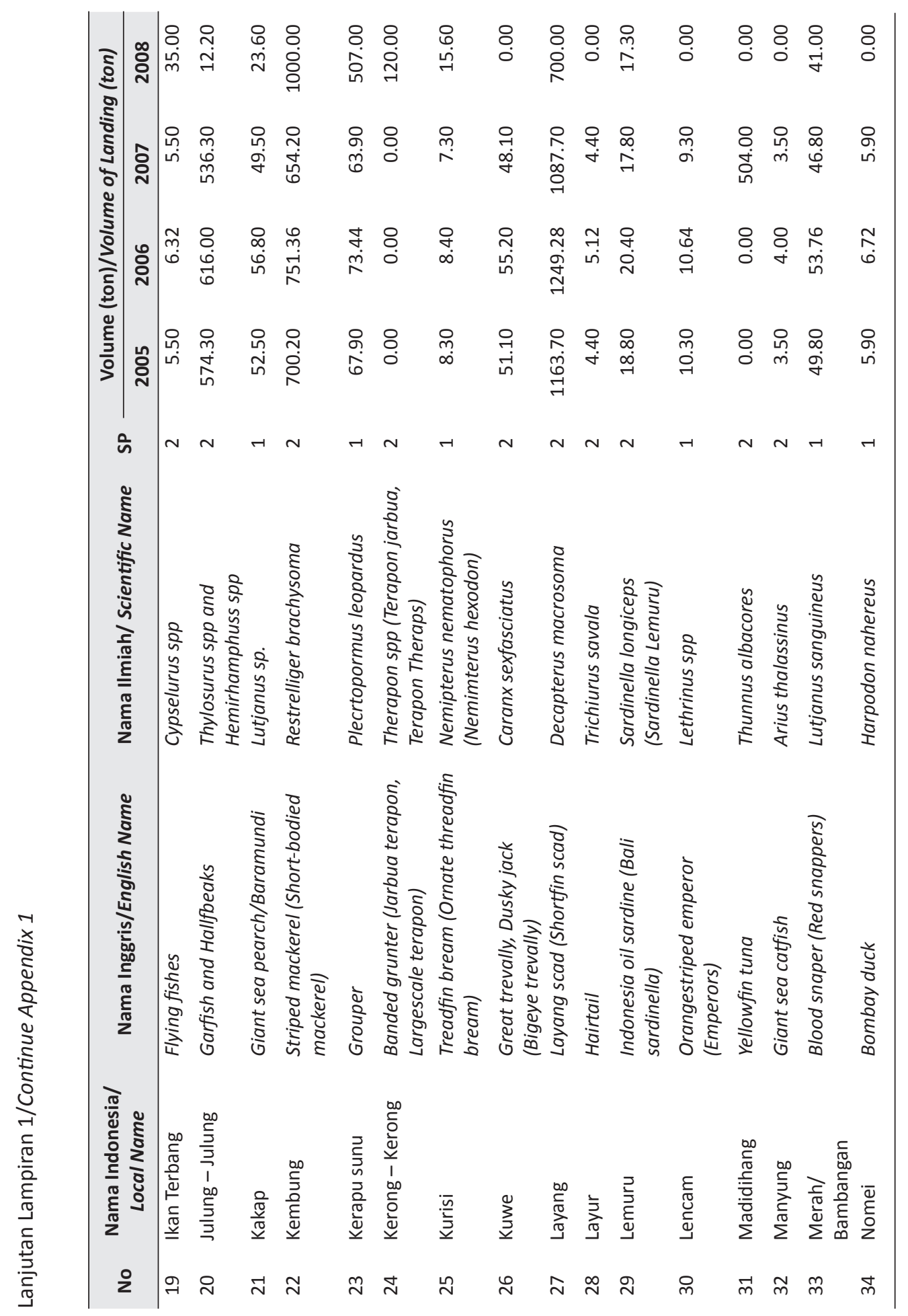




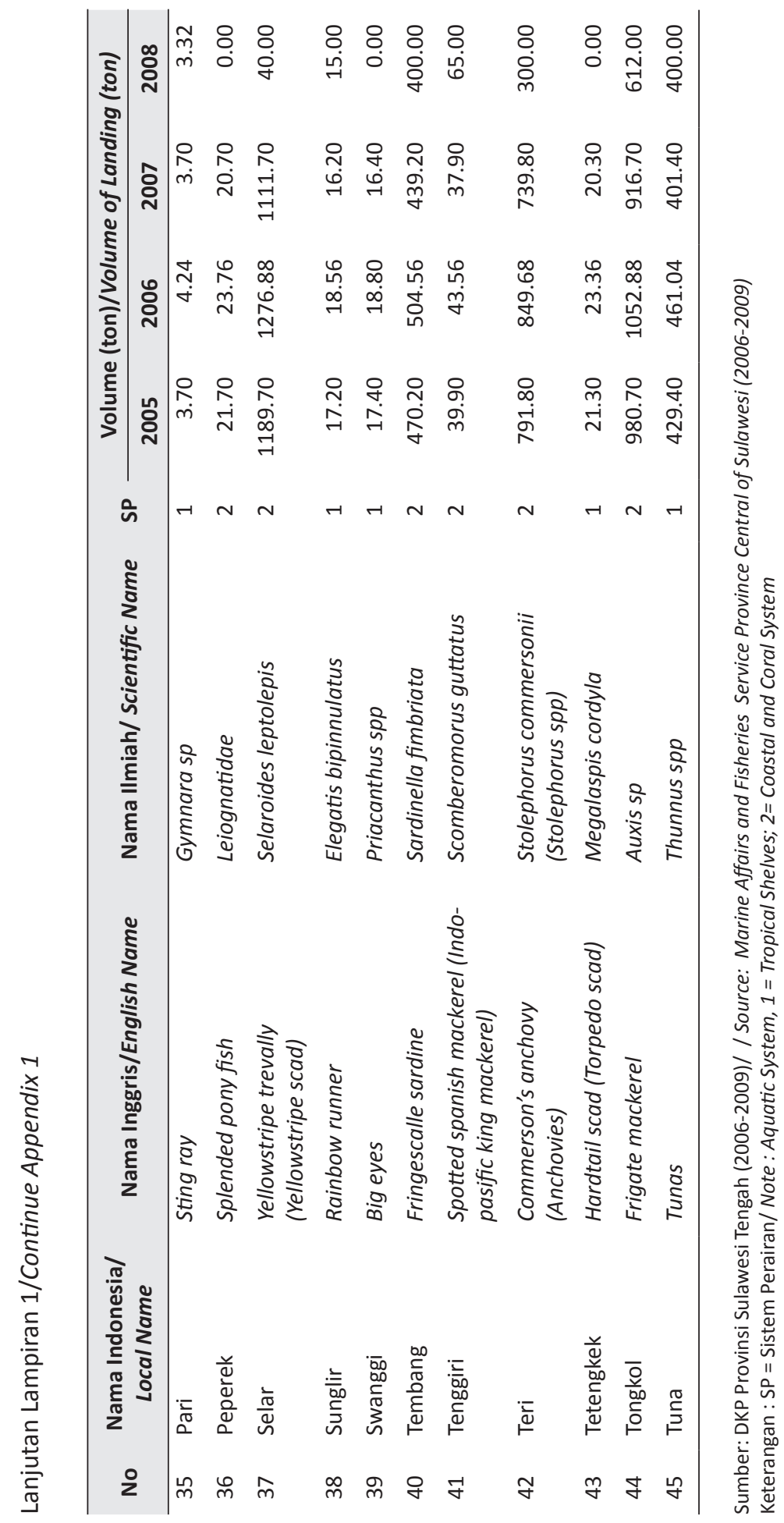




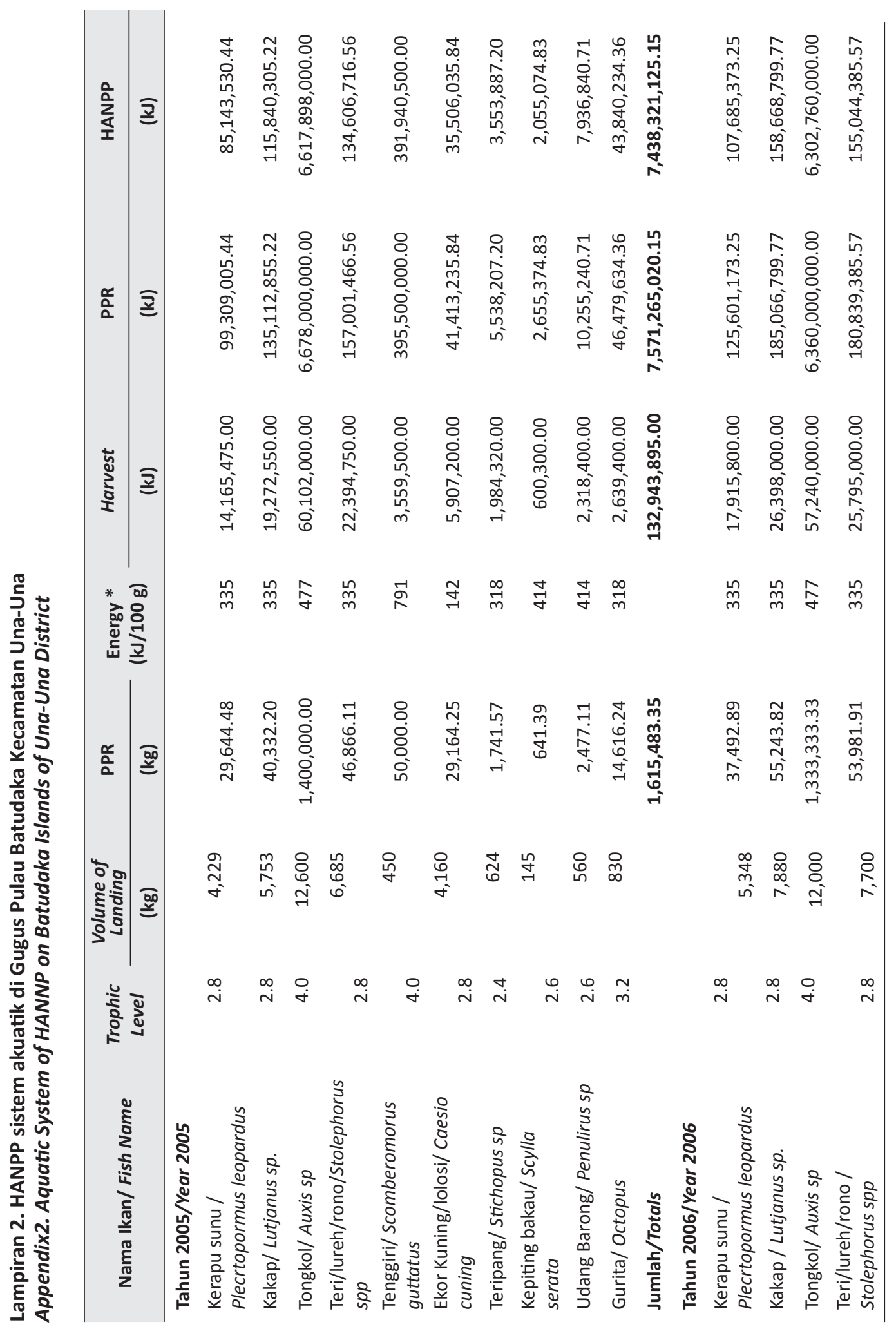




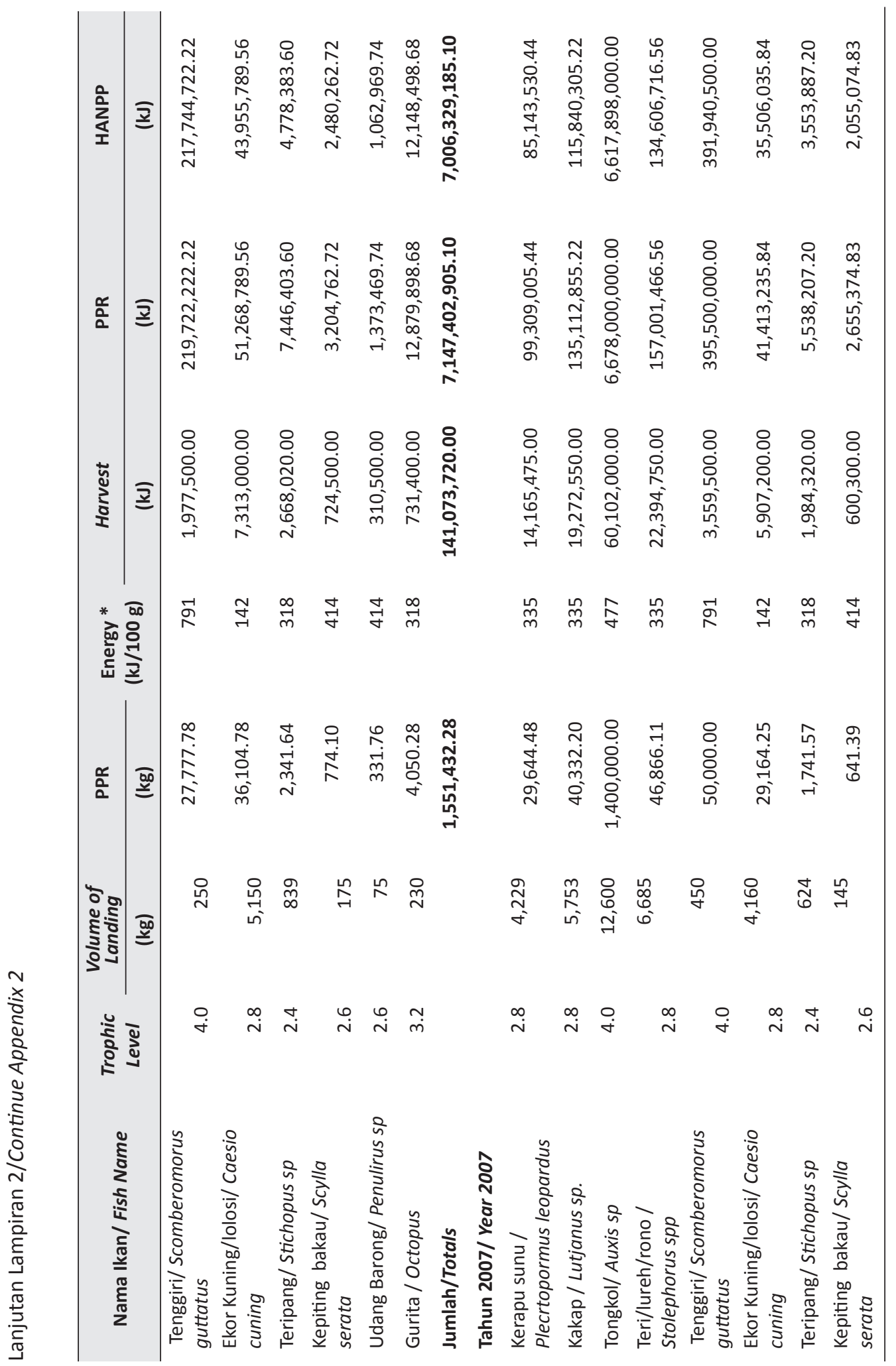




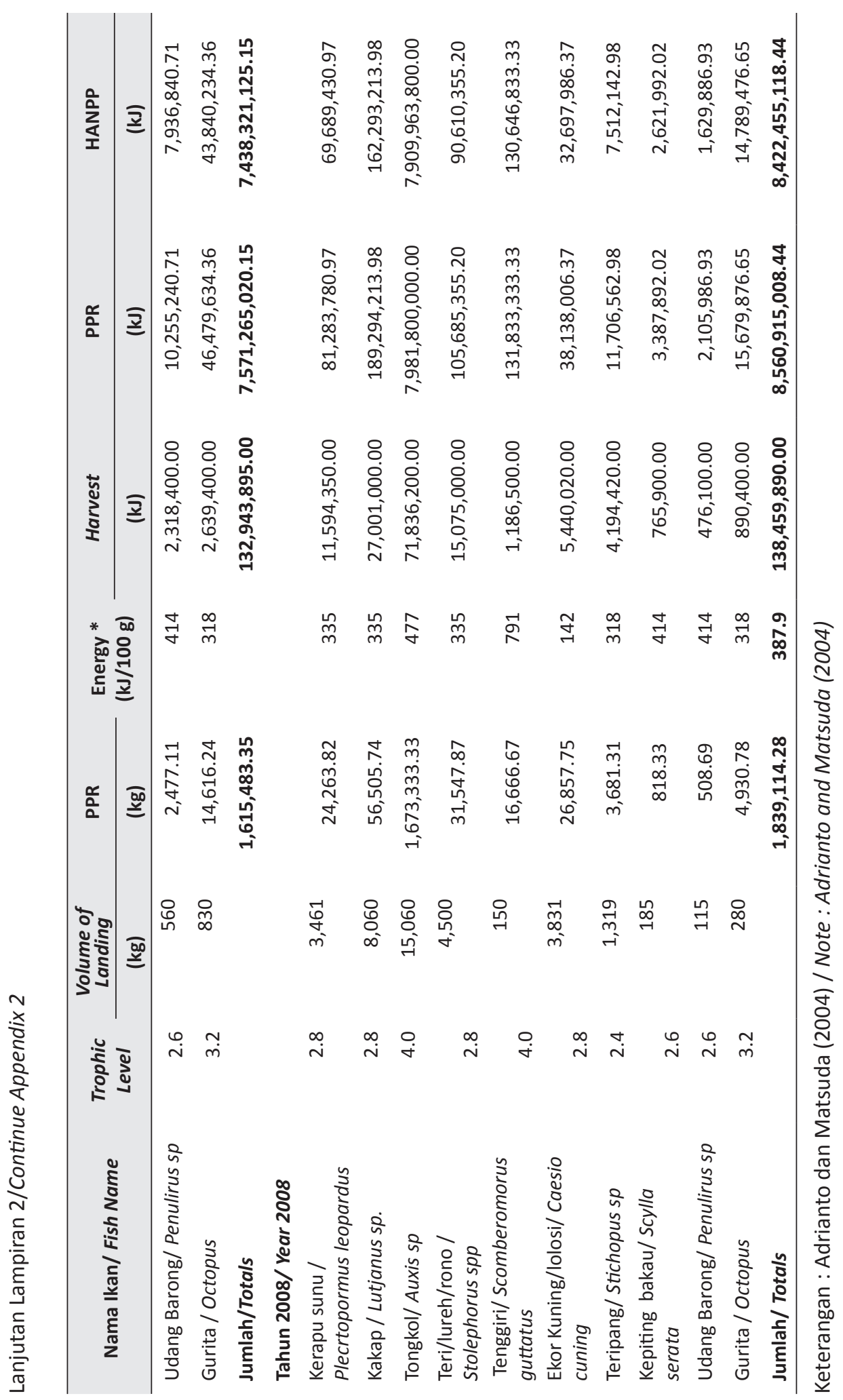

